\title{
DEMOCRACIA EM DUAS DIMENSÕES: cultura e instituições
}

\section{Carlos Vasconcelos Rocha*}

\begin{abstract}
Resumo: $\mathrm{O}$ autor analisa a relação entre a literatura que trata da configuração das instituições democráticas, em décadas recentes, e aqueles trabalhos que abordam as características da cultura política dos espaços urbanos. Argumenta sobre a necessidade de se viabilizar o diálogo entre as perspectivas teóricas culturalista e institucionalista, que, até agora, se desenvolvem de forma paralela e estanque.
\end{abstract}

Palavras-chave: democracia; participação; cultura política; instituições.

Uma temática que atualmente tem atraído a atenção dos cientistas sociais é a das condições do efetivo exercício da cidadania, especialmente das populações metropolitanas. Constatação bastante difundida na literatura que trata desse tema é que, nas últimas décadas, presenciamos um declínio na identificação das populações com as instituições democráticas liberais clássicas. Esse declínio se expressaria em um déficit crescente de participação política ou, pelo menos, num registro mais otimista, no desenvolvimento de novas formas diferenciadas da participação democrática tradicional. Partindo dessa tese, pretendemos desenvolver aqui algumas observações preliminares sobre a relação entre os trabalhos que tratam da configuração das instituições democráticas em décadas recentes e aqueles que abordam as características da cultura política

\footnotetext{
Doutor em Ciências Sociais pela Universidade Estadual de Campinas (Unicamp), professor e pesquisador do curso de pós-graduação em Ciências Sociais da PUC-Minas (mestrado e doutorado) e realizando estágio pós-doutoral no Instituto de Governo e Políticas Públicas (Igop) da Universidade Autônoma de Barcelona (UAB), com bolsa da Capes. E-mail: carocha@pucminas.br
}

Artigo recebido em 21 ago. 2008 e aprovado em 16 out. 2009. 
dos espaços urbanos. Em outras palavras, pretendemos desenvolver algumas observações sobre a relação entre as características contemporâneas do exercício da cidadania política - sustentadas por teses como Nova Cultura Política (NCP) ou declínio do espaço público, como veremos a seguir - e as características das instituições democráticas adotadas recentemente, baseadas nos princípios da democracia participativa.

Uma questão orientará nossa discussão: ao mesmo tempo em que se desenvolve uma institucionalidade democrática com base no ideal de cidadãos atentos à coisa pública, informados politicamente e interessados nas formas diretas e indiretas de participação política, ${ }^{1}$ numerosas pesquisas apontam para o declínio desse ideal de homem cívico. Sendo assim, teríamos uma contradição estabelecida: a valorização do poder local e da democracia participativa, como forma de "democratizar a democracia" - seja no plano do discurso, seja no plano da consolidação efetiva de espaços de participação dá-se na mesma medida em que se certa literatura aponta o declínio da identificação da população com as instituições democráticas. Dessa forma, haveria uma inadequação entre as características das instituições democráticas e o padrão de cultura política vigente. Segue-se, portanto, a seguinte questão: como relacionar o esforço de institucionalização democrática, que pressupõe considerável capacidade de participação cidadã, com esse virtual processo de declínio das formas tradicionais do comportamento cívico?

Temos assim um problema teórico, com conseqüências práticas evidentes, que diz respeito a como solucionar essas percepções contrastantes desenvolvidas no interior da teoria democrática. É desse aspecto que pretendemos tratar neste trabalho. Para tal, inicialmente, serão desenvolvidas algumas considerações sobre o processo de democratização recente. Posteriormente, abordaremos os argumentos das vertentes institucionalista e culturalista, que tratam das características e fundamentos da democracia. Finalmente, 
buscaremos argumentar sobre a necessidade de se viabilizar o diálogo entre as duas perspectivas teóricas que, até então, se desenvolvem de forma paralela e estanque.

\section{O processo de democratização recente}

O recente processo de democratização política instaurado em diversas partes do mundo, configurando o que se denominou a "terceira onda de democratização", foi caracterizado, em menor ou maior grau, pela capacidade de mobilização de diversos setores da sociedade civil, que reivindicavam seu direito de participação política. Para além das instituições da democracia representativa, atores filiados a correntes ideológicas diferenciadas reivindicavam a adoção de espaços compartidos de deliberação sobre decisões de políticas públicas entre a sociedade civil e o poder público. Esses atores argumentavam, cada qual com ênfases e justificativas específicas, que a descentralização se relacionaria positivamente com democracia, eficiência e inovação na gestão pública.

Nas últimas décadas do século XX, diferentes correntes de orientação política defendem, em diversos países, a descentralização político-administrativa do aparato estatal. Por exemplo, de 75 países em desenvolvimento, 63 adotaram reformas descentralizantes (Arretche, 1996). O desenvolvimento da democracia pressupõe, nesse sentido, o fortalecimento das instituições políticas locais, por viabilizar a participação dos cidadãos nas decisões públicas. Fortalecer institucionalmente e politicamente esses espaços de participação implicaria criar condições para a superação de problemas advindos do Estado centralizado, a saber: balcanização do poder público por elites econômicas e políticas; exercício de um poder ilegítimo da burocracia pública no processo de tomada de decisões; e a ação do Estado orientada pela lógica clientelista. A ampliação dos espaços de participação possibilitaria a vocalização de setores 
excluídos social, econômica e politicamente, ensejando a adoção de políticas redistributivas. Imaginava-se, assim, que inclusão política implicaria também inclusão econômica. Além disso, o exercício da participação implicaria educação para a cidadania, propiciando o desenvolvimento de virtudes cívicas, como: maior capacidade de iniciativa no espaço público, maior equidade e justiça social, e maior controle social sobre o Estado.

Fortalecer o poder local e instituir espaços de participação da sociedade civil no processo de tomada de decisões potencializaria a eficiência das ações públicas, neutralizando os interesses corporativos da burocracia e as barganhas clientelistas dos políticos. Isso possibilitaria a adequação das decisões públicas às reais demandas da sociedade, ensejando, também, a articulação de formas mais efetivas de fiscalização das ações governamentais. A proximidade entre a administração pública e a sociedade civil implicaria maior accountability e responsiveness. ${ }^{2}$

De fato, essas reivindicações são concretizadas em uma variedade de experiências participativas e de fortalecimento dos governos locais, marcando, em menor ou maior grau segundo o caso, o desenho das instituições públicas de diversos países. Como tendência mundial, guardadas as especificidades de cada caso, difundiu-se um conjunto de regras democráticas com a finalidade de criar espaços de participação da sociedade civil na definição de políticas públicas. Assim, experiências de participação local foram adotadas em diversos países, com cada um mantendo suas características específicas. ${ }^{3}$ Porém, entre as intenções e os fatos um longo caminho se fez presente.

Aquelas esperanças iniciais de democratização e de eficiência acabaram por se defrontar com as dificuldades surgidas no processo de consolidação de tais experiências. Na verdade, a literatura sobre o tema da participação, desenvolvida especialmente nas duas últimas décadas do século passado, era marcada por uma ênfase 
excessivamente normativa, até certo ponto ingênua, na defesa da descentralização como panacéia para os problemas da democracia e da gestão pública. Como os fatos se apresentam aquém do desejado, fica patente a necessidade de se examinar o padrão concreto de relação entre o Estado, as instituições políticas e a sociedade civil, visando aquilatar os efetivos resultados do processo de democratização. A distância que separa o que se almejou do que efetivamente se alcançou é algo a ser mensurado: o esforço de se avaliar o efetivo funcionamento dos diversos mecanismos de governo local e da democracia participativa, adotados nas últimas décadas, é ainda incipiente. As avaliações realizadas, até o momento, acabaram desenvolvendo uma controvérsia teórica que fornece aos pesquisadores duas opções analíticas distintas, cujos argumentos centrais serão expostos a seguir.

\section{Democracia, cultura e instituições}

Atualmente, o debate sobre a democracia organiza-se através da disjuntiva cultura política/desenho institucional. O sucesso dos espaços democráticos dependeria, para a perspectiva culturalista, das características da sociedade civil; já para a perspectiva institucionalista, o desenho e as características das instituições explicariam os resultados do processo de democratização. A questão de fundo, que demarca a polêmica, é se a cultura política explica o desenho das instituições políticas ou, antes, se o caráter das instituições - com a manutenção de regras e procedimentos específicos ao longo do tempo - produz uma cultura política afim. Em outros termos, o que está em jogo é se cultura produz instituições ou se instituições configuram cultura. Manguelle, por exemplo, afirma que "a cultura é a mãe; as instituições são os filhos" (apud Harrison, 2002). No campo oposto, a perspectiva institucionalista afirma que comportamentos cívicos seriam gerados por arranjos democráticos e não o inverso (Przeworski; Cheibub; Limongi, 2003). ${ }^{4}$ 
Neste trabalho, evitaremos tomar partido de um dos dois lados. Ao contrário, como se argumentará posteriormente, o objetivo é ressaltar a desejabilidade de um diálogo entre culturalismo e institucionalismo. Antes, contudo, serão desenvolvidos os argumentos de cada uma dessas perspectivas.

Os autores institucionalistas partem do pressuposto de que, ao cabo, a democracia não demanda uma cultura democrática para se consolidar. $\mathrm{O}$ foco de análise é direcionado para o que importa para eles: as instituições. Partem da concepção weberiana do Estado como organizador das relações sociais num determinado território. A chave do sucesso de ações públicas eficientes dependeria da existência de uma burocracia pública autônoma, coesa, coerente, disciplinada, tecnicamente preparada e com esprit de corps. Tais atributos evitariam a captura do Estado por grupos de interesses parciais. Nesse sentido, segundo Evans (1996), a falta de participação política não se deve a características da própria sociedade, mas à existência de instituições autoritárias que estabelecem relações verticais com os cidadãos. Em sociedades cujas instituições públicas se caracterizam pelo autoritarismo, coerção e clientelismo, a mobilização do poder local fica dificultada e as experiências participativas bem sucedidas não se generalizam. $\mathrm{O}$ Estado, como fator ativo de mobilização social e incentivador de redes cívicas, acaba por determinar o sucesso das iniciativas de participação.

Fox (1996), por sua vez, relaciona participação com o caráter dos dirigentes políticos. A participação se viabilizaria com a direção das instituições públicas por grupos reformistas favoráveis à intervenção política construtiva do Estado, comprometidos com história de lutas dos atores sociais e, ao mesmo tempo, capazes de propor soluções pragmáticas aos problemas coletivos. Para tal, essas lideranças políticas deveriam combinar um passado utópico com a experiência de derrotas, pois assim passariam a agir com certo pragmatismo. $\mathrm{O}$ fator essencial para a generalização de experiências 
de sucesso na mobilização da sociedade civil seria, portanto, a presença de elites governamentais reformistas e pragmáticas, comprometidas com a valorização de experiências de democracia participativa. Há aí, como podemos notar, clara relação entre as características requeridas para as elites políticas e a trajetória de atores vinculados à esquerda do espectro político.

As características culturais teriam, nessa visão, pouco efeito sobre o estabelecimento da democracia. Przeworski, Cheibub e Limongi (2003), por exemplo, apresentam evidências de que uma democracia pode se desenvolver em contextos de diferentes tradições culturais. Sustentam que "fatores econômicos e institucionais são suficientes para gerar uma explicação convincente da dinâmica das democracias sem que seja necessário recorrer à cultura” (p. 10).

Contrariamente, há autores que enfatizam as características culturais como decisivas para o estabelecimento da democracia. A democracia pressuporia a existência de uma correlata cultura democrática. Nesse sentido, "para que o modelo democrático do Estado participativo se desenvolva [...] é preciso mais que as instituições formais da democracia [...] requer também uma cultura congruente com ela" (Almond; Verba, 1965, p. 3). No caso, como se vê, o foco analítico é direcionado para as características da sociedade e a pesquisa em cultura política visa delinear empiricamente a emergência e a transformação gradual de padrões agregados de orientações "culturais" duradouras (valores, crenças, atitudes e assim por diante) e dos efeitos desses padrões na estabilidade e efetividade dos sistemas democráticos.

Em uma das vertentes da análise culturalista, a questão da participação democrática é analisada pela ótica da sociedade civil, com ênfase no conceito de capital social. Coleman (1990), um dos precursores dessa abordagem, estabelece o princípio de que a otimização do capital físico-econômico e humano é maior quando as relações de confiança e reciprocidade aumentam na comunidade. 
Nessa linha, Putnam (1996, p. 177), em trabalho sobre a Itália, propõe uma interpretação dos fundamentos do "bom governo" que se tornou referência no debate. Para ele, em todas as sociedades o dilema da ação coletiva obsta as tentativas de cooperação para benefícios mútuos. A cooperação voluntária dependeria do capital social, que diz respeito "a características da organização social, como confiança, normas e sistemas que contribuam para aumentar a eficiência da sociedade, facilitando as ações coordenadas". Putnam fundamenta seus argumentos na seguinte afirmação de Coleman: "como outras formas de capital, o capital social é produtivo, possibilitando certos objetivos que seriam inalcançáveis se ele não existisse..." (apud Putnam, 1996, p. 177). Mais que isso, afirma que o capital social instaura um círculo virtuoso que "redunda em equilíbrios sociais com elevados níveis de cooperação, confiança, reciprocidade, civismo e bem-estar coletivo" (p. 186). Ao contrário, a comunidade não-cívica instaura um círculo vicioso: "a deserção, a desconfiança, a omissão, a exploração, o isolamento, a desordem e a estagnação intensificam-se reciprocamente" (p. 187). As sociedades horizontais, cujas relações são mais igualitárias, caracterizam-se por maior grau de engajamento cívico. Portanto, nessa perspectiva, o governo local depende de um substrato cultural de capital social.

Essa perspectiva culturalista reverbera no trabalho de diversos autores que buscam definir os padrões culturais atuais. Esses autores concordam que as características culturais estão se modificando na atualidade, mas discordam sobre o significado dessas mudanças. Por um lado, alguns enfatizam o declínio do capital social e a deterioração da confiança da população nas instituições democráticas, com impactos deletérios para a democracia (Whithead, 1999, Putnam, 2000). Por outro lado, para outros autores, essas mudanças resultam em uma nova forma de fazer política, sem conseqüências necessariamente negativas para a democracia (Cabral; Silva, 2006, Clark; Inglehart, 1990). 
Tomemos, inicialmente, um trabalho de Putnam (2000) sobre o padrão de comportamento político atual nos Estados Unidos. ${ }^{5}$ Para ele, a sociedade cívica americana encontra-se em decadência e, em conseqüência, as bases da democracia estariam erodindo, já que "Every year over the last decade or two, millions more have withdrawn from the affairs of their communities" (p. 68). Ele acrescenta que "many major civic organizations have experienced a sudden, substantial, and nearly simultaneous decline in membership over the last decade or two" (p. 69). Essa tendência é detectada em sindicatos, igrejas, associação de pais e professores, e outras associações, bem como na abstenção eleitoral e na decrescente confiança nos governantes (p. 67).

Apesar do seu tom pessimista, Putnam qualifica a tendência de declínio do capital social nos Estados Unidos reconhecendo que outras formas de participação acabam se desenvolvendo, como, por exemplo, organizações de defesa do meio ambiente, grupos feministas, terceiro setor, grupos de auto-ajuda e outras modalidades de associação. No entanto, Putnam, diferentemente dos defensores da tese da Nova Cultura Política (NCP), como veremos a seguir, refuta que estariam se configurando novas formas de organização cívica. Segundo ele, as novas modalidades associativas não implicam aumento da confiança social, fundamento, segundo a teoria do capital social, das associações cívicas tradicionais. Exemplifica sua afirmação com os recém-difundidos grupos de auto-ajuda, cujas relações, segundo ele, são rarefeitas, sem capacidade de instaurar laços sociais duradouros.

Em outra vertente da perspectiva culturalista, Clark e Inglehart (1990) detectam a emergência de uma Nova Cultura Política (NCP). Vêem a difusão, em muitos países, de uma nova orientação ideológica, configurando uma transformação da política global, caracterizada por novas estruturas de lideranças, novas formas de participação cívica e política e pelo surgimento de novos problemas 
na agenda das sociedades. Tais modificações romperiam com os pressupostos da política tradicional, cujos conflitos organizam-se a partir das classes sociais e em torno de questões econômicas. No ocaso dessa tradição, a participação política passa a dar relevância a outras questões como raça, gênero, preferências sexuais, lealdades regionais e problemas ecológicos. A disputa política passa, portanto, a ser tencionada por uma diversidade de problemas sociais. A propriedade e o controle dos meios de produção deixa de ser o fator preponderante das relações políticas. A política deixa de se orientar pela clássica divisão entre esquerda e direita e, assim, segundo Clark e Inglehart (1990, p. 7): "ao nível do poder local [...] surgiram agentes políticos que são simultaneamente [...] fiscalmente conservadores e socialmente liberais".

Dessa forma, ao contrário da tese defendida por Putnam de que o capital social estaria em declínio, este, na perspectiva da NCP, estaria aumentando, resultante do incremento progressivo dos níveis educacional e de renda das pessoas, das experiências crescentes em viagens internacionais, do aumento das habilidades e das redes de comunicação, com o consequente aprofundamento da difusão de informações e das relações entre culturas, e da experiência crescente de participação em organizações voluntárias. Especialmente o crescimento da renda social permite, nessa visão, que as pessoas dediquem sua atenção a questões que dizem respeito ao estilo de vida e não apenas aos problemas econômicos. Além disso, haveria um aumento da tolerância com a diversidade de estilos de vida, principalmente pela influência da mídia.

Assim, uma nova forma de cidadania política estaria se desenvolvendo: os cidadãos ativistas passam a recusar o tratamento de clientes, contrapondo-se à burocracia tradicional, aos partidos políticos e às lideranças partidárias. Essas organizações hierárquicas ${ }^{6}$ estariam perdendo a relevância como referência da política. A própria estruturação da luta política modifica-se, dando lugar a 
outras formas de ação mais horizontais, tanto na esfera política como na esfera social, abrangendo, por exemplo, movimentos políticos, família e instituições educacionais. Essa transformação, no plano da cultura política, demanda, segundo os representantes da NCP, a descentralização do Estado, permitindo consolidar a autonomia apresentada pelas sociedades contemporâneas. Mais que descentralização, o que propõem é o retraimento da esfera estatal. Valorizam, por exemplo, que os cidadãos assumam responsabilidades sociais através de organizações sem fins lucrativos.

Clark e Inglehart (1990) observam, no entanto, que essas transformações estariam concentradas em algumas regiões específicas. Haveria maior probabilidade de desenvolvimento da NCP em lugares onde o grau de educação é maior, com economia de alta tecnologia e menos hierarquia na organização do trabalho, onde o protestantismo é mais difundido, e onde a incidência de relações clientelistas é menor. Além disso, a NCP estaria difundida predominantemente entre cidadãos e líderes políticos mais jovens e mais educados.

Outros autores enfatizam novos aspectos explicativos da difusão da NCP. Cabral e Silva (2006) apontam como pressuposto do desenvolvimento da NCP o que eles chamam de efeito-metrópole: efeitos da urbanização sobre formas de exercício da cidadania. ${ }^{7} \mathrm{Ou}$ seja, a tese do desenvolvimento de uma Nova Cultura Política (NCP), defendida por Clark e Inglehart, seria, nesse novo registro, uma manifestação do impacto da vida metropolitana nas modalidades de expressão cultural das pessoas. Essa relação entre cultura política e urbanização remonta a uma postulação clássica da sociologia urbana que concebe o exercício da cidadania como uma expressão característica do mundo urbano.

Antes de passar para o tópico final deste trabalho, vai aqui um parêntese para algumas considerações metodológicas que, ao cabo, reforçarão nossos argumentos em defesa da necessidade de uma 
abordagem mais ampla da questão democrática. Como se sabe, as pesquisas de cultura política dão grande ênfase à técnica de survey. No entanto, essa escolha metodológica pode apresentar problemas consideráveis. Não se pode negar que as avaliações expressas pelos cidadãos sobre as democracias, os sistemas institucionais e os governos são juízos a serem considerados por qualquer estudioso. Porém, como chamam a atenção alguns autores, além das palavras, as práticas devem ser uma unidade central de análise cultural. E há uma justificativa plausível para tal. O interesse em técnicas de survey focaliza a atenção em causas estruturais do comportamento, relacionando, por exemplo, concepções expressas sobre política com renda, nível educacional e outras varáveis. No entanto, negligencia sistematicamente a tarefa de estabelecer amarras sólidas numa teoria da ação intencional. Disso resulta uma atenção quase exclusiva à pesquisa em nível macro, com nenhum enraizamento no nível micro. O problema é que o contexto pode induzir a ações discrepantes com as concepções expressas pelos atores. Numa situação caracterizada pelo "dilema do prisioneiro", por exemplo, torna-se "irracional", na perspectiva individual, cooperar com os outros, mesmo que as pessoas concebam, idealmente, que a cooperação seria melhor e mais justa. ${ }^{8}$ Nesse sentido, Muller e Opp afirmam que: "A desvantagem da pesquisa de survey é que o contexto das situações particulares de escolha é não-controlado [...]. Deve-se supor que os valores e expectativas no momento da entrevista são aplicáveis a decisões comportamentais passadas e a potenciais decisões futuras, independentemente da variação no contexto da situação de escolha" (apud Johnson, 2004, p. 145). Assim, um aspecto a ser considerado são as "discrepâncias entre as atitudes tais como expressas em surveys e as manifestações comportamentais das atitudes" (Nieme apud Johnson, 2004 p. 145), pois não há garantia, e nem explicação teórica adequada, de convergência ou divergências entre a resposta de survey e a ação política. O survey detecta o que é declarado e não a ação efetiva. 


\section{Argumentos para um necessário diálogo entre cultura e instituições}

O estado de não diálogo das duas perspectivas analíticas consideradas neste trabalho configura a seguinte situação: a perspectiva culturalista tende a minimizar o papel das instituições e, por outro lado, o enfoque institucional tende a desconsiderar as condições sociais subjacentes à institucionalização. Tomando os argumentos mais extremados de cada perspectiva, a "visão culturalista forte" negligencia o papel das instituições na consolidação e na qualidade da democracia e a "visão instucionalista forte" entende que o estabelecimento e a sustentação da democracia independem de um substrato de cultura democrática ou cívica. Cremos que haveria um ganho analítico considerável pensar a democracia incorporando os resultados das pesquisas de ambas as perspectivas teóricas. Isso não no sentido de definir se cultura causa instituições ou vice-versa, mas sim de tentar estabelecer que tipo de correlação se configura entre ambas as perspectivas.

Os argumentos em favor de um diálogo entre as análises culturalista e institucionalista podem ser desenvolvidos de diversas maneiras. Insinuaremos algumas delas. Tomemos, por exemplo, as posições contrastantes no interior da perspectiva culturalista, uma mais otimista e outra mais pessimista, em sua relação com o perfil das instituições democráticas desenvolvido recentemente. Elas ganham um sentido analiticamente produtivo se cotejadas com as características das instituições democráticas adotadas nas últimas décadas. Em primeiro plano, a questão que deve ser respondida é se a configuração institucional recente é compatível com a chamada Nova Cultura Política (NCP), fornecendo espaços de manifestação de novos interesses através de novas formas de mobilização. Os institutos de deliberação democrática difundidos recentemente estariam, por exemplo, expressando uma nova NCP? Ou, por outro lado, haveria uma sobreposição inadequada entre uma NCP 
e instituições pensadas a partir de velhas formas de fazer política? Se for assim, haveria um potencial participativo inovador que não encontra ainda resposta no plano das instituições. Com referência à posição mais pessimista, o problema se apresenta de outra forma: a institucionalização democrática estaria se desenvolvendo a partir de uma visão de cidadania fadada à extinção, pois os espaços participativos estariam sendo adotados num momento de refluxo da participação e consequente esvaziamento do espaço público.

Expressão dessa falta de diálogo é o fato de que as pesquisas de cada uma dessas perspectivas, no geral, não se comunicam. Cada perspectiva tende a estabelecer seu campo próprio, cuja dinâmica se dá a partir do debate entre trabalhos com o mesmo foco analítico. De outra maneira, seria analiticamente desejável, por exemplo, estabelecer uma relação entre dados de survey sobre percepções de cidadania com informações relativas ao funcionamento efetivo de espaços de participação local. Relacionar essas dimensões pode representar um ganho analítico, por possibilitar revelar a adequação ou não das informações macro e micro, das intenções expressas e das ações efetivas contextualizadas. ${ }^{9}$

Por outro lado, o processo de gestação das instituições é ainda um aspecto pouco entendido nas Ciências Sociais. Se as instituições são cristalizações e, ao mesmo tempo, evidenciam os traços culturais de uma dada sociedade, as características da estruturação institucional de um país podem indicar maior ou menor cultura cívica. Assim, mais espaços institucionalizados de participação poderiam expressar uma intenção concreta de exercício da cidadania. Porém, alguns estudos mostram que, no geral, esses espaços participativos caracterizam-se pela baixa incidência de participação. Haveria, portanto, um descolamento entre o perfil das instituições e a cultura cívica (o que de alguma maneira é uma simplificação, pois certamente temos "culturas" convivendo numa mesma ordem social) Assim, relacionar ambas as dimensões é um 
desafio ainda a ser enfrentado pelos cientistas sociais: as perspectivas culturalista e institucionalista devem ser vistas como partes de um todo e o esforço analítico deve atentar para a relação da sociedade civil e das instituições com suas características específicas. O diálogo entre os resultados das pesquisas culturalista e institucionalista pode ajudar a pensar essa relação, com potencial promissor para se pensar adequadamente o desafio da construção da democracia.

\section{Notas}

1 Nesse sentido, é ilustrativa a retomada que Pateman (1992) faz do ideal participativo como fundamento da concepção democrática.

2 Ao lado desses argumentos que se referem ao tema da democracia, a defesa das virtudes do poder local é relacionada com o tema da globalização. Nesse sentido, o poder local é valorizado como forma de instaurar um movimento contra-hegemônico às forças globalizantes, especialmente o grande capital internacional.

3 No caso brasileiro, por exemplo, foram criados uma diversidade de espaços de participação como Conselhos deliberativos de políticas sociais, Orçamento Participativo, gestão participativa de escolas públicas e tantos outros.

4 As bases teóricas dessa controvérsia são remotas. Os argumentos culturalistas remontam, por exemplo, a Montesquieu, John Stuart Mill e Tocqueville e o institucionalismo tem referência em Max Weber.

5 Para desenvolver seus argumentos, Putnam compara dados de 14 surveys do General Social Survey, aplicados durante 20 anos. Ele trata especificamente do caso americano, mas afirma que as características encontradas no seu estudo de caso poderiam estar se repetindo em outros países.

6 Hierárquicas no sentido da diferenciação vertical de indivíduos ou grupos segundo critérios como renda, status e poder. 
7 Azevedo, Santos Junior e Ribeiro ([s.d.], p. 4) distinguem efeitometrópole de efeito-cidade da seguinte forma: "nas áreas mais urbanizadas, especialmente habitadas por setores homogêneos com maior capacidade de inserção social e econômica, tenderiam a prevalecer traços dessa cidadania pós-moderna, ou da NCP, em contraposição às demais áreas urbanas, que manteriam maior cristalização dos valores da cidadania clássica hegemônica do século passado".

8 Um bom exemplo desse dilema está em O'Donnell (1988).

9 Em recente e curioso estudo sobre os traços culturais dos brasileiros, Almeida (2007) relaciona atitudes cívicas e nível educacional, chegando à conclusão de que quanto mais educados formalmente, mais civicamente se comportam os brasileiros. Os resultados desse estudo, descartadas possíveis imprecisões metodológicas, ilustram bem os limites das pesquisas de survey. O senso comum, informado por experiências cotidianas, leva a receber de forma cautelosa as conclusões do autor de que as elites brasileiras, entre outras virtudes apontadas por ele, seriam mais cidadãs e que assim, como ironicamente colocou Veríssimo em crônica no Jornal do Brasil, não seriam merecedoras de nosso povo. A extrema desigualdade social, econômica e política cristalizada na sociedade brasileira não pode ser explicada sem, de alguma forma, apontar a contribuição de nossas elites - contribuição essa significativa para uma gama de trabalhos bastante significativos. Há, portanto, algo além do que os dados do trabalho de Almeida parecem demonstrar.

\title{
Democracy in two dimensions: culture and institutions
}

\begin{abstract}
The author analyses how scholars perceive democracy today. The writers who seek to explain the democratization process use cultural or institutional frameworks. However, the conclusion is that democracy should be studied by cultural and institutional factors. It is argued that this dialogue between both is needed.
\end{abstract}

Keywords: democracy; participation; political culture; institutions. 


\section{Referências bibliográficas}

ALMEIDA, Alberto Carlos. A cabeça do brasileiro. São Paulo: Record, 2007.

ALMOND, G.; VERBA, S. The civic culture. Boston: Little Brown, 1965.

ARRETCHE, Marta. Mitos da descentralização: mais democracia e eficiência nas políticas públicas? Revista Brasileira de Ciências Sociais, v. 11, n. 31, p. 44-66, 1996.

AZEVEDO, Sergio de; SANTOS JUNIOR, Orlando Alves; RIBEIRO, Luiz César de Queiroz. Cidade, cidadania e segmentações socioterritoriais no Brasil. Rio de Janeiro, [s.d.]. [não publicado].

CABRAL, Manuel Villaverde; SILVA, Filipe Carreira da. Cidade e cidadania: o "efeito-metrópole" sobre o exercício da cidadania política. Lisboa, 2006. [não publicado].

CLARK, Terry Nichols; INGLEHART, Ronald. The new political culture: changings dynamics of support for the welfare state and other policies in post-industrial societies. Madrid: ISA Congress, 1990.

COLEMAN, James. The fundations of social theory. Cambridge: Harvard University Press, 1990.

EVANS, Peter. Embedded autonomy: states and industrial transformation. Princeton: Princeton University Press, 1996.

FOX, Jonathan. How does civil society thicken? The political construction of social capital in rural Mexico. World Development, v. 24, n. 6, p. 1089-1103, 1996.

HARRISON, L. E. Introdução. In: HARRISON, L. E.; HUNTINGTON, S. P. (Orgs.). Cultura importa: os valores que definem o progresso humano. São Paulo: Record, 2002.

JOHNSON, J. Problemas conceituais como obstáculos ao progresso em Ciência Política. Teoria e Sociedade, v. 12, n. 1, 2004. 
O’DONNEL, Guilhermo. Situações: microcenas da privatização do público em São Paulo. Novos Estudos: Cebrap, n. 22, 1988.

PATEMAN, C. Participação e teoria democrática. Rio de Janeiro: Paz e Terra, 1992.

PRZEWORSKI, A.; CHEIBUB. J. A.; LIMONGI, F. Democracia e cultura: uma visão não culturalista. Lua Nova: Revista de Cultura e Política, n. 58, p. 9-35, 2003.

PUTNAM, R. Comunidade e democracia. Rio de Janeiro: Ed. FGV, 1996.

Bowling alone: the collapse and revival of American community. New York: Simon e Schuster, 2000.

WHITEHEAD, L. Jogando Boliche no Bronx: os interstícios entre a sociedade civil e a sociedade política. Revista Brasileira de Ciências Sociais, n. 14, p. 15-30, 1999. 